\title{
Transcranial approaches for pituitary adenomas: current indications and clinical and radiological outcomes
}

\author{
Mohamed M. Salama and Mohamed Reda Rady
}

\begin{abstract}
Background: The indications of transcranial approaches for pituitary adenomas have declined in the last decades with the widespread performance of endoscopic transsphenoidal approaches.

The aim of the study was to review the current indications of transcranial approaches for pituitary adenomas and to evaluate the clinical and radiological outcome following these approaches.

Patients and methods: This study included 16 patients with fresh, residual, or recurrent pituitary adenomas operated upon by transcranial approaches alone or in combination with transsphenoidal approaches. The indication to perform a transcranial approach was reviewed for each patient. Postoperative clinical outcome and the extent of tumor resection were assessed.

Results: The indications of transcranial approaches were significant parasellar and/or anterior fossa extensions in 6 patients, failed previous transsphenoidal surgery in 3 patients, giant adenoma extending into the third ventricle in 3 patients, dumbbell-shaped adenoma in 2 patients, and doubtful diagnosis in 2 patients. Two patients with invasive giant adenomas were operated upon by a combined approach. There was a single mortality. Permanent complications included visual loss in one patient, third nerve palsy in one patient, hypopituitarism in two patients, and permanent diabetes insipidus in two patients. Gross total resection was achieved in one patient, subtotal resection in seven patients, and partial resection in eight patients.

Conclusion: Transcranial approaches are still needed for some complex pituitary adenomas particularly giant tumors with significant lateral, anterior, or superior extensions, tumors with fibrous consistency particularly after failure of transsphenoidal approach, and dumbbell-shaped tumors with severe constriction at the diaphragm.
\end{abstract}

Keywords: Transcranial approaches, Pituitary adenomas, Giant adenomas

\section{Introduction}

During the last decades, the transsphenoidal approaches had become the standard and the first line option for surgical management of pituitary adenomas. These approaches have been proven to be effective and safe, being minimally invasive approaches that avoid the need for craniotomy with less hospitalization time and less morbidity and mortality [1-3]. The advances in

\footnotetext{
*Correspondence: Mohamed.reda@kasralainy.edu.eg

Department of Neurosurgery, Faculty of Medicine, Cairo University, 57 Sudan St., Cairo, Egypt
}

\section{Springer Open}

(c) The Author(s). 2021 Open Access This article is licensed under a Creative Commons Attribution 4.0 International License, which permits use, sharing, adaptation, distribution and reproduction in any medium or format, as long as you give appropriate credit to the original author(s) and the source, provide a link to the Creative Commons licence, and indicate if changes were made. The images or other third party material in this article are included in the article's Creative Commons licence, unless indicated otherwise in a credit line to the material. If material is not included in the article's Creative Commons licence and your intended use is not permitted by statutory regulation or exceeds the permitted use, you will need to obtain permission directly from the copyright holder. To view a copy of this licence, visit http://creativecommons.org/licenses/by/4.0/. definition optics and the widespread use of the extended transsphenoidal approaches had decreased the indications for transcranial approaches with only less than $5-$ $10 \%$ of pituitary adenomas being operated upon using transcranial approaches [4-9].

The current indications for transcranial approaches include tumors with dumbbell-shaped configuration due to hourglass constriction at the diaphragm, multilobulated tumors, tumors with large intracranial extensions and small sellar volume, tumors with asymmetric extension into the anterior fossa, tumors with significant 
lateral extensions, and fibrous tumors $[5,9,10]$. Although the endoscopic transsphenoidal approaches including the extended approaches have managed to deal with some of these tumors efficiently, the transcranial approaches are still required for some tumors particularly those with significant lateral tumor extensions beyond the cavernous sinus or the supraclinoid internal carotid artery [8-11]. Transcranial approaches are also indicated in cases with failed previous transsphenoidal surgery particularly for fibrous tumors and as a part of combined transcranial and transsphenoidal approaches for some giant and invasive adenomas whether simultaneously or staged to increase the extent of resection $[6$, $12-14]$. Other less common indications for transcranial surgery include doubtful preoperative diagnosis, kissing carotid arteries making the transsphenoidal approach hazardous, and the coexistence of an aneurysm with the adenoma $[6,10]$.

The aim of the study was to review the current indications for transcranial approaches for pituitary adenomas and to evaluate the outcome following these approaches both clinically and radiologically.

\section{Patients and methods}

This study was conducted on 16 patients with pituitary adenomas operated upon by transcranial approaches alone or combined transcranial and transsphenoidal approaches during the period between 2009 and 2017. This study included pituitary adenomas operated upon for the first time in addition to residual and recurrent adenomas.

All patients have been subjected to thorough history taking and detailed neurological examination with particular emphasis on assessment of visual acuity, visual field by confrontation, fundus examination, and assessment of ocular motility. Automated perimetry was performed for all conscious patients with visual acuity better than 1/60, and hormonal profile was requested for all patients except in one patient in whom the lesion was not suspected to be an adenoma preoperatively. Magnetic resonance imaging (MRI) with intravenous injection of gadolinium was performed for all patients.

Patients were operated upon by transcranial approaches including the subfrontal, the frontolateral, and the pterional approaches. All patients were admitted to the intensive care unit and initial clinical assessment was performed in the immediate postoperative period. Any conscious level deterioration or the occurrence of any unexplained neurological deficit was immediately investigated by computed tomography (CT) of the brain; otherwise, CT brain was performed on the second postoperative day. Postoperative evaluation stressed on assessment of the conscious level, visual acuity and field, ocular motility, motor power, and manifestations of hypopituitarism including diabetes insipidus (DI). MRI with contrast was performed after 3 months for all patients.

Data of these patients including age, sex, clinical presentation, visual assessment, ocular motility, hormonal profile, and MRI findings were reviewed. The indication to perform a transcranial approach was reviewed for each patient. Postoperative clinical outcome in the early postoperative period and at the last follow-up and the extent of tumor resection as verified by postoperative MRI were assessed. Analysis of the indications to perform a transcranial approach or a combined transsphenoidal and transcranial approach was performed retrospectively to determine the few indications for transcranial approaches.

\section{Results}

The study included 12 male patients and 4 female patients with mean age of 35 years (range 10-57 years). Visual affection was the main presenting symptom with eight patients $(50 \%)$ presenting with diminution of vision. Three patients (18.75\%) presented with slight conscious level disturbance with all three patients having visual affection. Two patients (12.5\%) presented with visual field affection and two patients (12.5\%) presented mainly with headache and mild visual affection. One patient (6.25\%) presented with acromegalic features in the form of change in body features and size of extremities. Examination revealed some degree of visual deterioration or field defect in all patients with ten patients (62.5\%) having marked diminution of vision in one or both eyes where marked visual affection was defined as visual acuity less than 1/60. Endocrinological manifestations were present in five patients (31.25\%); four of them were males with impotence and diminished secondary sexual characters, and the last patient was acromegalic.

The hormonal profile was normal apart from mild hyper-prolactinemia due to stalk effect in 11 patients (68.75\%). Two patients (12.5\%) had markedly elevated prolactin levels $(8000$ and $8800 \mathrm{ng} / \mathrm{ml}$ ), one patient (6.25\%) had elevated growth hormone (GH) levels, and one patient (6.25\%) had mild reduction in serum cortisol levels. Hormonal profile was not obtained in one patient $(6.25 \%)$ with a lesion that was not preoperatively suspected to be a pituitary adenoma on MRI but turned out to be an adenoma intraoperatively with postoperative diagnosis of prolactinoma. Seven patients $(43.75 \%)$ had macroadenomas (>1 cm in maximum tumor diameter) and nine patients $(56.25 \%)$ had giant adenomas $(>4 \mathrm{~cm}$ in maximum tumor diameter). Eight patients $(50 \%)$ had invasive pituitary adenomas with bilateral cavernous sinus invasion present in three patients (18.75\%). Six patients (37.5\%) had significant parasellar extension and/or anterior fossa extension and four patients (25\%) had 
large suprasellar extension obliterating the third ventricle. Three patients (18.75\%) had hydrocephalus on their preoperative images; two patients (12.5\%) were managed by initial cerebrospinal fluid (CSF) diversion by ventriculoperitoneal (VP) shunt, while the third patient (6.25\%) was operated upon by direct tumor attack followed by VP shunt few weeks later. There were three patients $(18.75 \%)$ who were previously operated upon; one patient was operated upon by transsphenoidal approach that failed to reach the adenoma, one patient was operated upon twice by the transsphenoidal approach, and one patient has been operated upon twice using transcranial approaches and once by a transsphenoidal approach. The duration between the initial surgery and the final surgery ranged between 1 week and 3 years.

The indications for surgery in these patients included disturbed conscious level in 3 patients (18.75\%), acromegaly in 1 patient (6.25\%), and visual affection in 12 patients (75\%). The indications to perform transcranial approaches were adenomas with significant parasellar extensions and/or anterior fossa extensions in six patients (37.5\%), giant adenoma with extension into the third ventricle in three patients (18.75\%), failed previous transsphenoidal surgery in three patients (18.75\%), dumbbell-shaped adenoma with a waist at the diaphragm in two patients (12.5\%), and doubtful diagnosis in two patients (12.5\%) (Fig. 1). Patients with failed previous transsphenoidal surgery included two patients with failed surgery due to fibrous and tough tumor consistency and one patient with the transsphenoidal surgery misdirected into the anterior cranial fossa due to a small poorly pneumatized sphenoid sinus. Two patients (12.5\%) were operated upon by a combined approach where a transsphenoidal approach was performed followed by a transcranial approach. Both patients had invasive giant adenomas with large suprasellar extension obliterating the third ventricle in one patient (6.25\%) and significant parasellar extension in the other patient (6.25\%). Both patients had tumor extension into the sphenoid sinus so a combined approach was performed. The preoperative MRI of three cases with doubtful diagnosis, significant lateral tumor extension, and significant suprasellar tumor extension obliterating the third ventricle are shown in Figs. 2, 3, and 4, respectively.

Seven patients $(43.75 \%)$ were operated upon by the pterional approach, six patients (37.5\%) were operated upon by the unilateral subfrontal approach, and three patients $(18.75 \%)$ were operated upon by the frontolateral approach. Twelve patients (75\%) were operated upon from the right side and 4 patients (25\%) were operated upon from the left side. The left side was performed in patients with tumors with anterior or lateral extensions predominantly on the left side.

There was a single mortality (6.25\%) in this series in a patient with an invasive giant adenoma occupying the third ventricle that was operated upon by VP shunt followed by a combined approach. The patient developed severe hypernatremia and agitation postoperatively which gradually resolved over few days but the patient developed ventriculitis with disturbed conscious level. The VP shunt was externalized; however, the patient developed sepsis and died from septic shock 2 weeks after surgery. Four patients $(25 \%)$ were sleepy in the early postoperative period and they improved within few days and were fully conscious on discharge from the hospital. Postoperative clinical assessment revealed visual improvement in eight patients $(50 \%)$, stationary vision in seven patients $(43.75 \%)$, and visual loss in one patient $(6.25 \%)$ with severe visual affection preoperatively. Visual

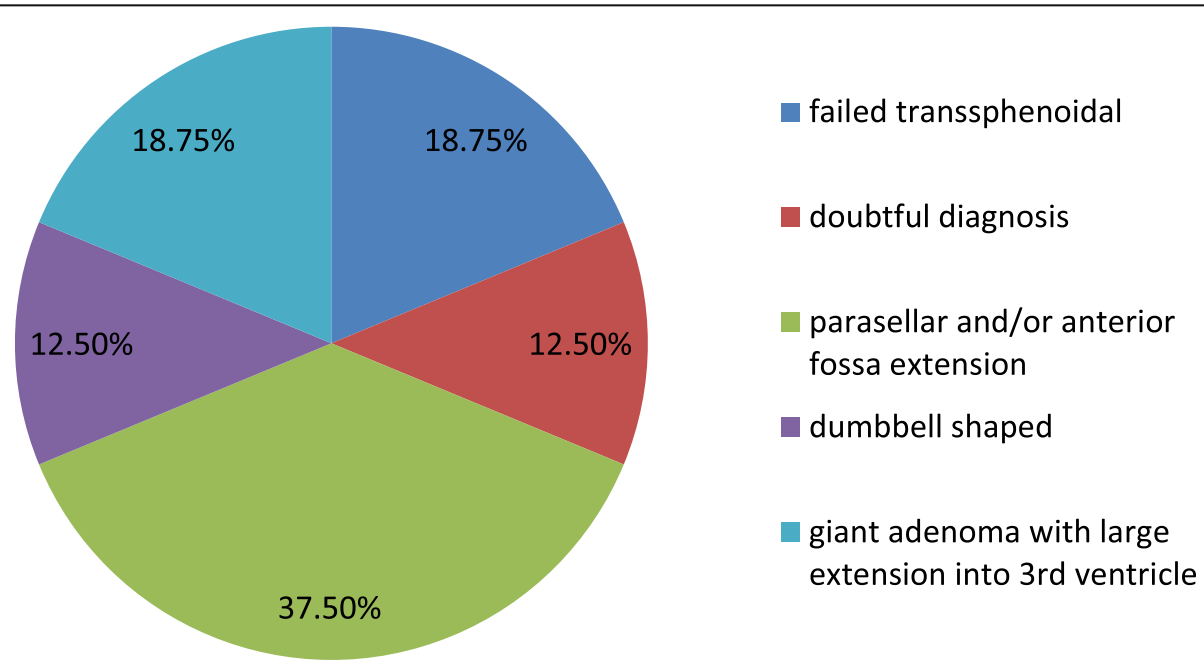

Fig. 1 A chart showing indications for transcranial surgery 


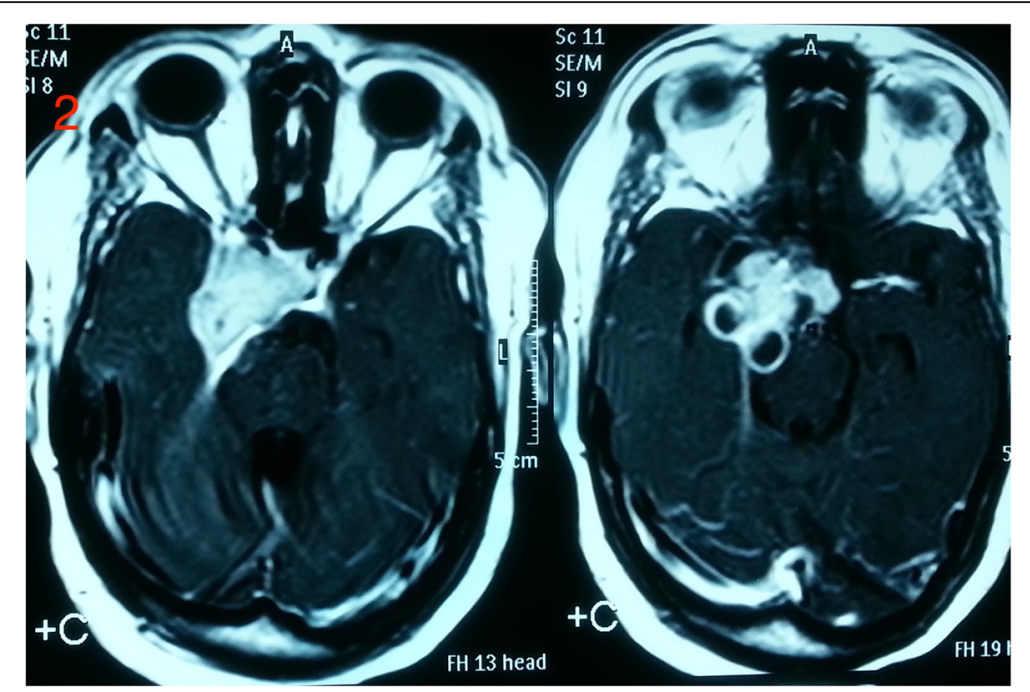

Fig. 2 MRI brain T1WI with contrast showing a case with doubtful diagnosis

deterioration in this patient might be explained by ischemia to the optic nerve or by mechanical trauma during dissection of the tumor from the already thinned out optic nerve. Two patients (12.5\%) developed postoperative third nerve palsy which was temporary in one patient (6.25\%) and permanent in one patient (6.25\%) in whom a trial of tumor removal from the cavernous sinus was performed. Two patients (12.5\%) developed temporary hemiparesis that recovered within few days in both patients. Four patients (25\%) developed temporary DI and were given vasopressin for periods ranging from few weeks to 6 months and two patients (12.5\%) developed permanent DI. Two patients (12.5\%) developed hypopituitarism and required replacement therapy. One patient $(6.25 \%)$ had postoperative fits and was controlled by antiepileptics and one patient (6.25\%) with transsphenoidal surgery performed few days before the transcranial approach developed CSF leak that stopped within few days. Table 1 shows the permanent complications in our series.
Gross total resection was achieved in only one patient (6.25\%) who had a growth-hormone secreting macroadenoma, subtotal resection ( $>90 \%$ ) leaving a small tumor residue mainly in the cavernous sinus was achieved in seven patients $(43.75 \%)$ while debulking with partial resection was achieved in eight patients (50\%). The main causes for partial resection included firm tumor consistency in two patients (12.5\%) and tumor extensions beyond safe surgical resection in six patients (37.5\%). The residual tumor was managed by medical treatment alone in two patients $(12.5 \%)$ and by medical treatment in addition to radiosurgery in another patient $(6.25 \%)$ with prolactinoma. Regarding the 11 patients (75\%) with residual nonfunctioning adenomas, 8 patients (50\%) were followed up both clinically and radiologically, while three patients (18.75\%) were referred to radiosurgery. The follow-up period ranged between 2 to 8 years with mean follow-up period of 4 years. Figure 5 shows MRI of a patient with subtotal resection with a small residual left in the cavernous sinus.

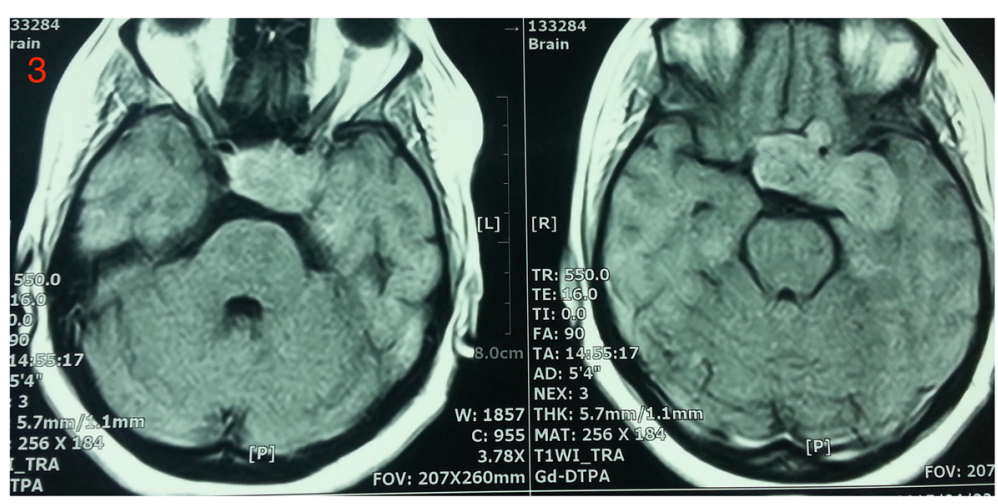

Fig. $3 \mathrm{MRI}$ brain T1WI with contrast showing a case with significant lateral tumor extension 


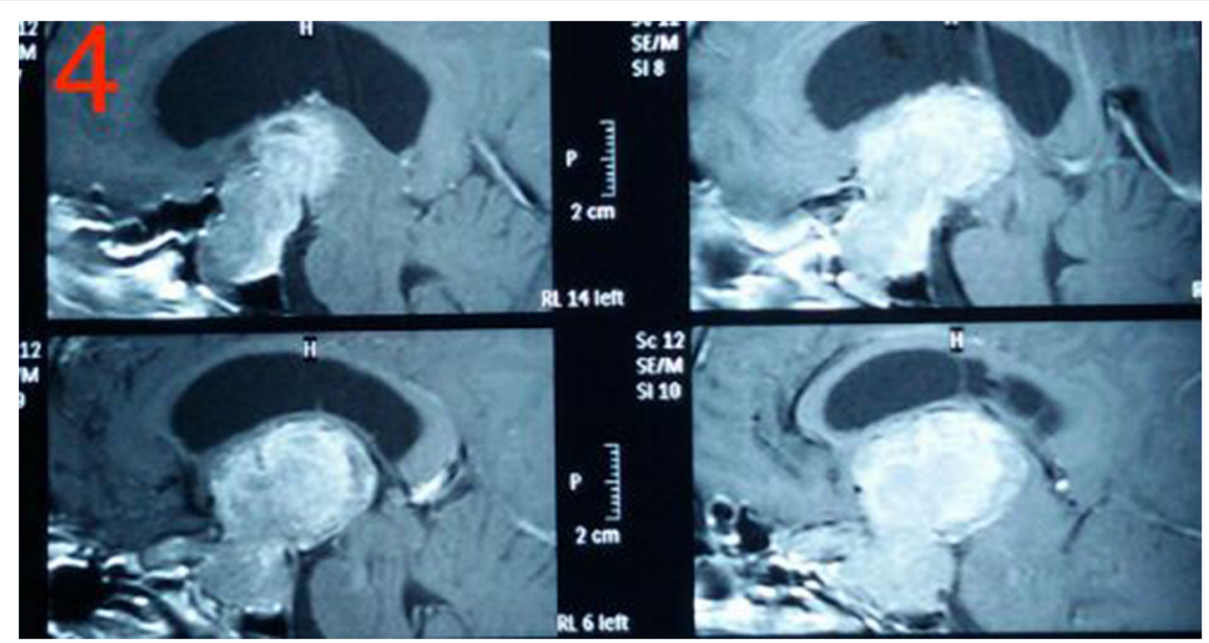

Fig. $4 \mathrm{MRI}$ brain T1WI with contrast showing a case with large suprasellar extension obliterating the third ventricle

\section{Discussion}

After performing retrospective analysis of the different indications for performing transcranial approaches, we found that the most common indication in our series was significant tumor extensions into the parasellar region and/or the anterior cranial fossa which constituted $37.5 \%$ of our cases. Although gross total resection was not achieved in any of these patients, subtotal resection leaving a small residual mainly in the cavernous sinus was achieved in four of these six patients (67\%). A combined approach was performed in one of these patients who had significant tumor extension in the sphenoid sinus in addition to the significant intracranial tumor extension, a policy recommended also by Nishioka et al. and Ojha et al. in selected giant adenomas [12, 13]. In cases with parasellar extension, our goal was to decompress the optic apparatus and reduce the tumor burden. The residual tumor was managed by either medical treatment and/or radiosurgery or just followed up. Several studies encourage safe excision of adenomas while leaving the cavernous portion for radiosurgery $[9,10$, $15]$ as long as an adequate margin exists between the residual tumor and the optic apparatus $(>5 \mathrm{~mm}$ ) [16] or for medical treatment which is very effective in patients with prolactinomas. Koutourousiou et al. reported that tumors extending into the lateral cavernous sinus and the middle fossa could not be totally resected unless a transcranial approach was performed; however, they

Table 1 Permanent complications

\begin{tabular}{ll}
\hline Complication & Number of patients (percentage) \\
\hline Visual loss & $1(6.25 \%)$ \\
Third nerve palsy & $1(6.25 \%)$ \\
Diabetes insipidus & $2(12.5 \%)$ \\
Hypopituitarism & $2(12.5 \%)$ \\
\hline
\end{tabular}

recommended managing these lesions with transsphenoidal approaches admitting that a residual might be left in the middle fossa with minimal risk. They stated that lesions with significant anterior fossa extension might need a combined endonasal and transcranial approach [8].

Another common indication was giant adenomas with large suprasellar extension obliterating the third ventricle which constituted $18.75 \%$ of our cases. In all of these patients, gross total or subtotal resection was not achieved and only debulking with partial resection was performed leaving a residual tumor in the third ventricle. One of these patients was operated upon by a combined approach due to significant sphenoid sinus extension which was adequately removed by the transsphenoidal approach before dealing with the transcranial extension few days later. Significant suprasellar extension into the third ventricle was considered as an indication for transcranial surgery by Pratheesh et al. and Buchfedler et al. $[5,9]$. Koutourousiou et al. did not consider this as an indication for transcranial surgery and recommended expanded endoscopic approach for such lesions especially that it provides a direct access along the tumor axis [8]. Kassam et al., Ikeda et al., and Cappabinaca et al. reported favorable outcomes following extended transsphenoidal approaches for these lesions $[4,15,17]$.

Failed previous transsphenoidal approach was the indication to perform transcranial surgery in $18.75 \%$ of the cases, mainly due to fibrous tumor consistency. Although this indication is not currently approved by some authors who perform extracapsular tumor resection using the same principles applied in transcranial surgery [17-19], other authors still consider it as an indication to operate transcranially $[8,9,14]$. Although dumbbellshaped tumors with large suprasellar extension was considered as the most common current indication by 


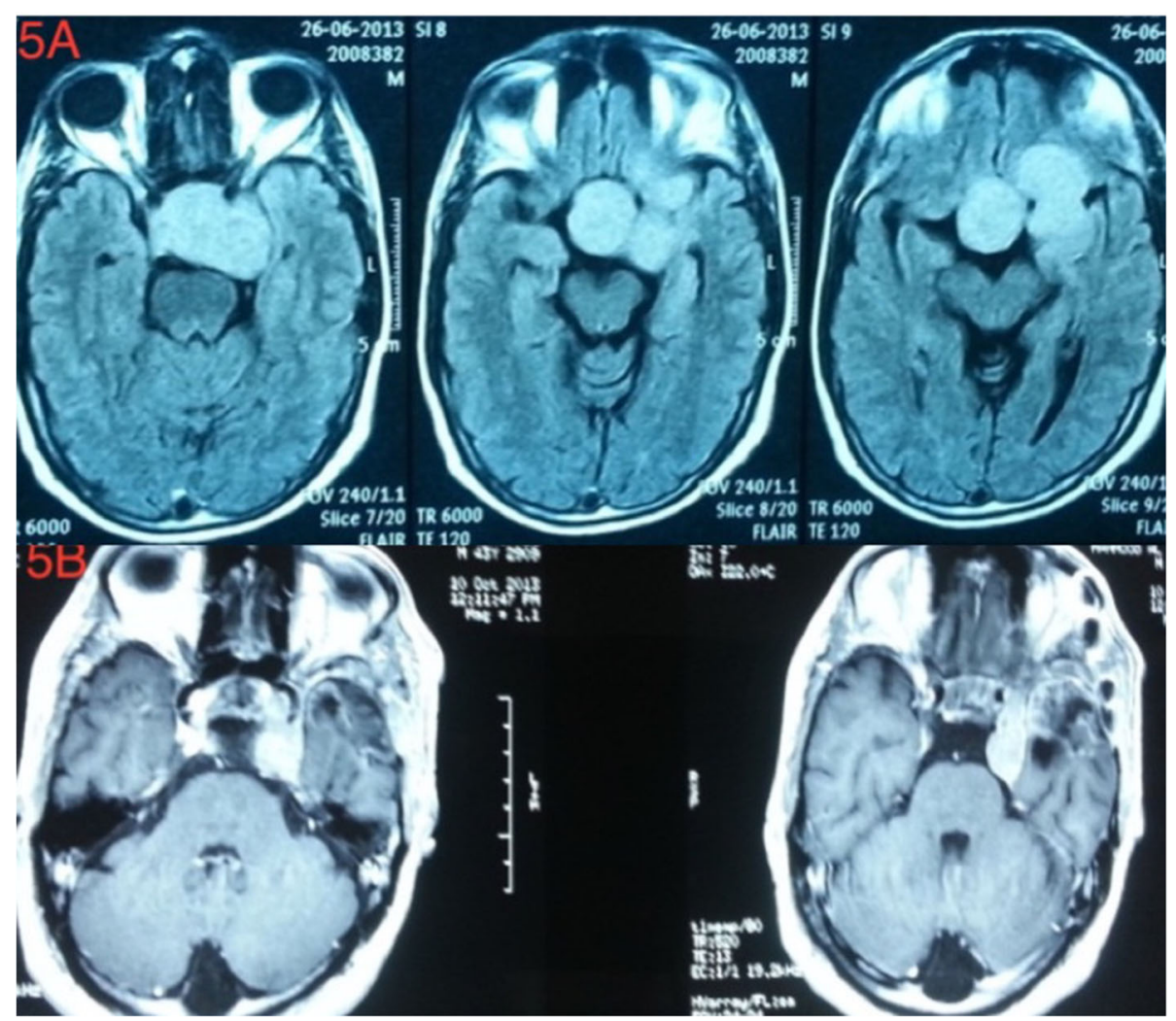

Fig. 5 A Preoperative MRI Brain showing lateral tumor extension into and lateral to the cavernous sinus. B Postoperative MRI Brain showing subtotal tumor resection leaving a small residual in the left cavernous sinus

several authors [8-10], it was the indication in only $12.5 \%$ of our patients. Another option to manage dumbbell shaped tumors with significant constriction at the diaphragm is through the transsphenoidal transdiaphragmatic approach which needs further bony drilling and sectioning of the diaphragm with the resultant higher incidence of cerebrospinal fluid leak [19]. Doubtful diagnosis as an indication for transcranial approaches markedly declined with the high-quality MRI images that make the diagnosis of a pituitary adenoma almost certain in most of the cases nowadays. However, several authors still consider it as an indication for transcranial approach [6,20]. The two cases with doubtful diagnosis were suspected to be meningiomas so a transcranial approach was decided. Although many surgeons operate nowadays on meningiomas through the expanded endonasal approaches with drilling of the planum sphenoidale and tuberculum sella reporting favorable results [4, 17], we did not feel comfortable to approach these cases through a transsphenoidal approach particularly with the unavailability of navigation in the operating room.

It is well known that the rate of complications and the incidence of hormonal deficiency are much lower with transsphenoidal approaches $[2,3,21]$. In our transcranial series, the mortality rate was $6.25 \%$ which is comparable to other series in the microscopic era where the reported mortality rates following transcranial resection of pituitary adenomas ranged between 0 and $8.7 \%$ [9, 22, 23]. Regarding the visual outcome, there was visual deterioration in only $6.25 \%$ of cases which is comparable to the results of Guo et al. and lower than the 13\% reported by Pratheesh et al. [9, 22]. Visual improvement occurred in only $50 \%$ of cases which is much lower than the rates reported in several transsphenoidal and transcranial series $[8,9,22,23]$ and might be explained by the severe preoperative visual deterioration in the majority of our patients. Panhypopituitirism requiring replacement therapy occurred in $12.5 \%$ of cases while DI developed in $37.5 \%$ of the cases being permanent in only $12.5 \%$ of patients. Guo et al. reported hypopituitarism in $13 \%$ of cases and temporary diabetes insipidus in $80 \%$ of cases with no cases with permanent diabetes insipidus [22]. Pratheesh et al. also reported hypopituitarism in $30 \%$ of the cases and DI in $26 \%$ of the cases being permanent in only $8.7 \%$ of cases [9].

Gross total resection or near total resection were achieved in $56.25 \%$ of the cases which is similar to the results reported by Pratheesh et al. who achieved resection $>90 \%$ in $56.5 \%$ of their patients but lower than the incidence reported by Guo et al. who achieved gross 
total resection in $67 \%$ of cases $[9,22]$. Komotar et al. in their systematic review of approaches to giant adenomas found that gross total resection was achieved in $9.6 \%$ of the cases and near total resection (> 80-90\%) was achieved in $90.4 \%$ of the cases [24]. The majority of our cases were complex cases with either giant and/or invasive tumors. Near total resection was achieved in all cases with dumbbell shaped adenoma and in most of the cases with parasellar extension; however, in cases with fibrous adenomas and significant extension into the third ventricle near total resection could not be achieved.

\section{Conclusion}

Transcranial approaches are still needed for the management of some complex pituitary adenomas particularly those giant tumors with significant lateral and anterior extensions, those with fibrous consistency particularly after failure of transsphenoidal approach, and dumbbell shaped tumors with severe constriction at the diaphragm. Giant tumors with large suprasellar extension obliterating the third ventricle might be approached transcranially; however, similar results can be achieved using the expanded endoscopic approaches by experienced surgeons.

\section{Abbreviations}

CT: Computed tomography; CSF: Cerebrospinal fluid; DI: Diabetes insipidus; $\mathrm{GH}$ : Growth hormone; MRI: Magnetic resonance imaging;

VP: Ventriculoperitoneal

\section{Acknowledgments}

Not applicable.

\section{Authors' contributions}

Both authors collect and analyze the data together. The author(s) read and approved the final manuscript.

\section{Authors' information}

Mohamed Salama is a professor of neurosurgery in Cairo University. Mohamed Reda Rady is an assistant professor of neurosurgery in Cairo University and a consultant in a children cancer hospital in Egypt.

\section{Funding}

There is no any funding.

Availability of data and materials

All the data and the materials are available.

\section{Declarations}

\section{Ethics approval and consent to participate}

Our ethical approval details for our retrospective study: date was 7/11/2018 signed by our head of department and ethical committee prof Mohamed Hafez Ramadan.

\section{Consent for publication}

Not applicable.

\section{Competing interests}

The authors declare that they have no competing interests.
Received: 29 April 2020 Accepted: 31 May 2021

Published online: 27 September 2021

\section{References}

1. Jho HD, Carrau RL. Endoscopic endonasal transsphenoidal surgery: experience with 50 patients. J Neurosurg. 1997;87(1):44-51. https://doi.org/1 0.3171/jns.1997.87.1.0044.

2. Cappabianca P, Cavallo LM, de Divitiis E. Endoscopic endonasal transsphenoidal surgery. Neurosurgery. 2004;55(4):933-41. https://doi.org/1 0.1227/01.NEU.0000137330.02549.0D.

3. Kassam AB, Prevedello DM, Carrau RL, Snyderman CH, Thomas A, Gardner P, et al. Endoscopic endonasal skull base surgery: analysis of complications in the authors' initial 800 patients. J Neurosurg. 2011;114(6):1544-68. https:// doi.org/10.3171/2010.10.JNS09406.

4. Kassam A, Snyderman CH, Mintz A, Gardner P, Carrau RL. Expanded endonasal approach: the rostrocaudal axis. Part I. Crista galli to the sella turcica. Neurosurg Focus. 2005;19:E3.

5. Buchfelder M, Kreutzer J. Transcranial surgery for pituitary adenomas. Pituitary. 2008;11(4):375-84. https://doi.org/10.1007/s11102-008-0120-8.

6. Jane JA Jr, Thapar K, Laws ER Jr. Pituitary tumors: functioning and nonfunctioning. In: Winn HR, editor. Youmans Neurological Surgery. 6th ed. Philadelphia: Saunders; 2011. p. 1476-510.

7. De Divitiis E, De Divitiis O. Surgery for large pituitary adenomas: what is the best way? World Neurosurg. 2012;77(3-4):448-50. https://doi.org/10.1016/j. wneu.2011.09.044

8. Koutourousiou M, Gardner P, Fernandez-Miranda JC, Paluzzi A, Wang EW, Snyderman $\mathrm{CH}$. Endoscopic endonasal surgery for giant pituitary adenomas: advantages and limitations. J Neurosurg. 2013;118(3):621-31. https://doi. org/10.3171/2012.11.JNS121190.

9. Pratheesh R, Rajaratnam S, Prabhu K, Mani SE, Chacko G, Chacko AG. The current role of transcranial surgery in the management of pituitary adenomas. Pituitary. 2013;16(4):419-34. https://doi.org/10.1007/s11102-0120439-z.

10. Youssef AS, Agazzi S, van Loveren HR. Transcranial surgery for pituitary adenomas. Oper Neurosurg. 2005;57(suppl_1):168-75. https://doi.org/10.122 7/01.NEU.0000163602.05663.86.

11. Couldwell WT. Transsphenoidal and transcranial surgery for pituitary adenomas. J Neurooncol. 2004;69(1-3):237-56. https://doi.org/10.1023/B: NEON.0000041886.61149.ab.

12. Ojha BK, Husain M, Rastogi M, Chandra A, Chugh A, Husain N. Combined trans-sphenoidal and simultaneous trans-ventricular-endoscopic decompression of a giant pituitary adenoma: case report. Acta Neurochir (Wien). 2009;151(7):843-7. https://doi.org/10.1007/s00701-009-0336-z.

13. Nishioka H, Hara T, Usui M, Fukuhara N, Yamada S. Simultaneous combined supra-infrasellar approach for giant/large multilobulated pituitary adenomas. World Neurosurg. 2012;77(3-4):533-9. https://doi.org/10.1016/j.wneu.2011.07. 013.

14. Recinos PF, Goodwin CR, Brem H, Quinones-Hinojosa A. Transcranial surgery for pituitary macroadenomas. In: Quinones-Hinojosa A, editor. Schmidek \& Sweet Operative Neurosurgical Techniques, ed 6th. Philadelphia: Elsevier Saunders; 280. p. 291-2012.

15. Ikeda H, Jokura H, Yoshimoto T. Transsphenoidal surgery and adjuvant gamma knife treatment for growth hormone-secreting pituitary adenoma. J Neurosurg. 2001;95(2):285-91. https://doi.org/10.3171/jns.2001.95.2.0285.

16. Pollock BE, Kondziolka D, Lunsford LD, Flickinger JC. Stereotactic radiosurgery for pituitary adenomas: imaging, visual and endocrine results. Acta Neurochir Suppl. 1994;62:33-8. https://doi.org/10.1007/978-3-7091-93 71-6_7.

17. Cappabianca P, Cavallo LM, Esposito F, De Divitiis O, Messina A, De Divitiis E. Extended endoscopic endonasal approach to the midline skull base: the evolving role of transsphenoidal surgery. Adv Tech Stand Neurosurg. 2008; 33:151-99. https://doi.org/10.1007/978-3-211-72283-1_4.

18. Schwartz TH, Fraser JF, Brown S, Tabaee A, Kacker A, Anand VK. Endoscopic cranial base surgery: classification of operative approaches. Neurosurgery. 2008;62(5):991-1005. https://doi.org/10.1227/01.neu.0000325861.06832.06.

19. Kaptain GJ, Vincent DA, Sheehan JP, Laws ER. Transsphenoidal approaches for the extracapsular resection of midline suprasellar and anterior cranial base lesions. Neurosurgery. 2008;62(6 Suppl 3):1264-71. https://doi.org/1 0.1227/01.neu.0000333791.29091.83.

20. Adams C. Transcranial surgery for pituitary macroadenomas. In Schmidek HH (ed): Schmidek and Sweet's Operative Neurosurgical Techniques. 
Indications, Methods, and Results. 5th ed. Philadelphia: Saunders; 2005. p. 348-54.

21. Jane JA, Han J, Prevedello DM, Jagannathan J, Dumont AS, Laws ER. Perspectives on endoscopic transsphenoidal surgery. Neurosurg Focus. 2005;19:E2.

22. Guo F, Song L, Bai J, Zhao P, Sun H, Liu X, et al. Successful treatment for giant pituitary adenomas through diverse transcranial approaches in a series of 15 consecutive patients. Clin Neurol Neurosurg. 2012;114(7):885-90. https://doi.org/10.1016/j.clineuro.2012.01.033.

23. Sinha S, Sharma BS. Giant pituitary adenomas--an enigma revisited. Microsurgical treatment strategies and outcome in a series of 250 patients Br J Neurosurg. 2010;24(1):31-9. https://doi.org/10.3109/026886909033703 05.

24. Komotar RJ, Starke RM, Raper DMS, Anand VK, Schwartz TH. Endoscopic endonasal compared with microscopic transsphenoidal and open transcranial resection of giant pituitary adenomas. Pituitary. 2012;15(2):1509. https://doi.org/10.1007/s11102-011-0359-3.

\section{Publisher's Note}

Springer Nature remains neutral with regard to jurisdictional claims in published maps and institutional affiliations.

\section{Submit your manuscript to a SpringerOpen ${ }^{\circ}$ journal and benefit from:}

- Convenient online submission

- Rigorous peer review

- Open access: articles freely available online

High visibility within the field

- Retaining the copyright to your article

Submit your next manuscript at $\boldsymbol{\nabla}$ springeropen.com 